\title{
The Contribution of Ecstasy Dependence and Stress to Ecstasy/MDMA- Related Psychiatric Symptoms
}

\author{
R. Margherita Milani*, ${ }^{*}$, John Turner ${ }^{2}$ and Andy C. Parrott ${ }^{3}$
}

${ }^{I}$ Thames Valley University, Faculty of Health and Human Sciences, London, UK

${ }^{2}$ University of East London, Department of Psychology, London, UK

${ }^{3}$ Department of Psychology, Swansea University, Swansea, UK

Keywords: Ecstasy dependence, MDMA dependence, stress, BSI, psychiatric symptoms, anxiety, depression.

Table 1. Multiple Regression Analysis Results

\begin{tabular}{|c|c|c|c|c|c|}
\hline BSI & ANOVA & R Square & Significant Predictors & Beta & P Value \\
\hline Somatization & $\begin{array}{c}\mathrm{F}_{(14,228)}=5.15 \\
\mathrm{p}<0.001\end{array}$ & 0.178 & $\begin{array}{c}\text { Age } \\
\text { Stress } \\
\text { Last time of E use } \\
\text { E p. dependence }\end{array}$ & $\begin{array}{l}-0.320 \\
0.140 \\
0.132 \\
0.153\end{array}$ & $\begin{array}{c}<0.001 * * * \\
0.020^{* *} \\
0.020^{*} \\
0.023^{*}\end{array}$ \\
\hline Anxiety & $\mathrm{F}_{(10,218)}=5.25, \mathrm{p}<0.001$ & 0.155 & $\begin{array}{c}\text { Stress } \\
\text { Family history } \\
\text { E p. dependence }\end{array}$ & $\begin{array}{l}0.286 \\
0.194 \\
0.188\end{array}$ & $\begin{array}{c}<0.001 * * * \\
0.004 * * \\
0.004 * *\end{array}$ \\
\hline Obsessive Compulsive Disorders & $\mathrm{F}_{(14,228)}=3.58, \mathrm{p}<0.001$ & 0.127 & $\begin{array}{c}\text { Stress } \\
\text { Age } \\
\text { Polydrug use }^{1} \\
\text { E p. dependence }\end{array}$ & $\begin{array}{l}0.268 \\
-0.174 \\
0.175 \\
0.154\end{array}$ & $\begin{array}{l}0.008^{* *} \\
0.015^{*} \\
0.024^{*} \\
0.038^{*}\end{array}$ \\
\hline Depression & $\mathrm{F}_{(12,212)}=3.27, \mathrm{p}<0.001$ & 0.164 & $\begin{array}{l}\text { E p. dependence } \\
\text { Stress } \\
\text { Family History }\end{array}$ & $\begin{array}{l}0.246 \\
0.222 \\
0.151 \\
\end{array}$ & $\begin{array}{l}0.001 * * \\
0.001 * * \\
0.025^{*}\end{array}$ \\
\hline Interpersonal Sensitivity & $\mathrm{F}_{(8,215)}=6.014, \mathrm{p}<0.001$ & 0.213 & $\begin{array}{l}\text { E dependence } \\
\text { Stress } \\
\text { Family history }\end{array}$ & $\begin{array}{l}0.289 \\
0.190 \\
0.179\end{array}$ & $\begin{array}{c}<0.001 * * * \\
0.003 * * \\
0.021 *\end{array}$ \\
\hline Anger Hostility & $\mathrm{F}_{(13,211)}=3.83, \mathrm{p}=0.001$ & 0.186 & $\begin{array}{l}\text { E p. dependence } \\
\text { Stress }\end{array}$ & $\begin{array}{l}0.231 \\
0.189\end{array}$ & $\begin{array}{l}0.003 * * \\
0.008 * *\end{array}$ \\
\hline Phobic Anxiety & $\mathrm{F}_{(13,203)}=6.84, \mathrm{p}<0.001$ & 0.226 & $\begin{array}{c}\text { Stress } \\
\text { Family history } \\
\text { E p. dependence }\end{array}$ & $\begin{array}{l}0.286 \\
0.188 \\
0.171 \\
\end{array}$ & $\begin{array}{c}<0.001 * * * \\
0.004 * * \\
0.011^{*}\end{array}$ \\
\hline Paranoid Ideation & $\mathrm{F}_{(13,203)}=5.92, \mathrm{p}<0.001$ & 0.238 & $\begin{array}{l}\text { E p. dependence } \\
\text { Stress } \\
\text { Last time of E use } \\
\text { Usual N of tablets } \\
\text { Age }\end{array}$ & $\begin{array}{c}0.367 \\
0.203 \\
0.160 \\
0.196-0.140\end{array}$ & $\begin{array}{c}<0.001 * * * \\
0.001 * * \\
0.016^{*} \\
0.022^{*} \\
0.045^{*}\end{array}$ \\
\hline Psychoticism & $\mathrm{F}_{(13,203)}=4.40, \mathrm{p}<0.001$ & 0.220 & $\begin{array}{l}\text { Family history } \\
\text { Stress } \\
\text { E p. dependence }\end{array}$ & $\begin{array}{l}0.245 \\
0.207 \\
0.148 \\
\end{array}$ & $\begin{array}{c}<0.001 * * * \\
0.001 * * \\
0.040^{*} \\
\end{array}$ \\
\hline General Symptoms Distress & $\mathrm{F}_{(14,197)}=4.72, \mathrm{p}<0.001$ & 0.266 & $\begin{array}{l}\text { Stress } \\
\text { E p. dependence } \\
\text { Family History }\end{array}$ & $\begin{array}{l}0.258 \\
0.245 \\
0.174\end{array}$ & $\begin{array}{c}0.001^{* *} \\
0.001 * * \\
0.013^{*}\end{array}$ \\
\hline
\end{tabular}

E p dependence: Ecstasy psychological dependence.

$* \mathrm{p}<0.05,{ }^{* *} \mathrm{P}<0.01, * * * \mathrm{p}<0.001$.

\section{INTRODUCTION}

A range of psychiatric symptoms are prevalent in regular users of recreational Ecstasy [1], and this has been linked to

*Address correspondence to this author at the Thames Valley University, Faculty of Health and Human Sciences, London, UK;

Tel: 0044 (0) 793142 8813; E-mail: Raffaella.Milani@tvu.ac.uk
MDMA's neurotoxic potential [2]. However, there are still many areas of uncertainty. This study investigated the relative contributions of dosage, perceived stress, age, gender, family psychiatric history, and Ecstasy dependency, to the psychopathological profiles of a non-clinical polydrug cohort. 


\section{METHOD}

The sample comprised 501 young people ranging from non-drug users to heavy Ecstasy polydrug users; participants were allocated into four groups: alcohol and/or tobacco users, polydrug users who had never taken Ecstasy, light Ecstasy polydrug users (Ecstasy on less than 20 occasions), and heavy Ecstasy polydrug users ( +20 occasions). All respondents completed the Brief Symptoms Inventory (BSI), a family and personal psychiatric history questionnaire [3], and a detailed drug/Ecstasy use questionnaire [3], which included five questions on physical and psychological dependence. For the multiple regression analysis, the ecstasy psychological dependence score was created from 3 questions. Finally, a 3 point self-rated item was used as an indication of level of stress the last 6 months (1- More than usual; 2- same as normal; 3 - Less than usual).

\section{RESULTS}

Ecstasy users reported higher scores than alcohol/tobacco users on 8 out of 9 BSI subscales. 14\% of the Ecstasy user sample met criteria of ecstasy dependence, while $20 \%$ had felt dependent on MDMA sometime in their life. Multiple regression identified three main predictors for elevated BSI scores: extent of ecstasy dependence, level of stress experienced in the previous six months and presence of psychiatric disorders in the immediate family, results are displayed in Table 1. In contrast, there was no significant association between Ecstasy dose and regimen variables and the BSI dimensions. There was a significant interaction indicating that level of stress increased global pathology score (GSI) only when the degree of psychological dependence was high $(\mathrm{p}=0.45)$.

\section{DISCUSSION}

A growing body of evidence [4] has found that common neurobiological pathways and abnormalities may underpin addiction and several psychiatric disorders; this might explain why in this study extent of Ecstasy dependence was strongly associated with elevated psychopathology.
Furthermore, stress has been found to be crucial in unmasking vulnerability to both substance use disorders and psychiatric disorders [5]. Accordingly, findings presented here suggest that Ecstasy users who develop Ecstasy dependence might become less able to cope with stress, or it is possible that people who are less able to cope with high levels of stress might be prone to develop Ecstasy dependence. The fact that presence of mental illness in the family was also predictive of elevated psychopathology supports the idea that some people might be predisposed to develop psychological problems following ecstasy use [6, 7].

\section{CONCLUSIONS}

Ecstasy psychological dependence was a better predictor of psychological problems than lifetime Ecstasy/MDMA dosage. Those with high levels of Ecstasy dependence were also less able to cope with adverse life events. Pre-existing vulnerability to psychiatric disorders should also be taken into account.

\section{REFERENCES}

[1] Sumnall HR, Wagstaff GF, Cole JC. Self-reported psychopathology in polydrug users. J Psychopharmacol 2004; 18: 75-82.

[2] Parrott AC, Milani R, Parmar R, Turner JJD. Ecstasy polydrug users and other recreational drug user's psychiatric symptoms. Psychopharmacology 2001; 159: 77-82.

[3] Milani RM, Parrott AC, Schifano F, Turner JJ. Pattern of cannabis use in ecstasy polydrug users: moderate cannabis use may compensate for self-rated aggression and somatic symptoms. Hum Psychopharmacol 2005; 20(4): 249-61.

[4] Brady KT, Sinha. Co-occurring mental and substance use disorders: The neurobiological effects of chronic stress. Am J Psychiatry 2005; 162: 1483-93.

[5] Sinha R. How does stress increase risk of drug abuse and relapse? Psychopharmacology 2001; 158: 343-59.

[6] Soar K, Turner JJD, Parrott AC. Psychiatric disorders in recreational ecstasy (MDMA) users: a literature review focusing upon personal predisposition factors and drug histories. Hum Psychopharmacol 2001; 16: 641-6.

[7] Lieb R, Schuetz CG, Pfister H, von Sydow K, Wittchen H. Mental disorders in ecstasy users: prospective-longitudinal investigation. Drug Alcohol Depend 2002; 68: 195-207.

This is an open access article licensed under the terms of the Creative Commons Attribution Non-Commercial License (http://creativecommons.org/licenses/ by-nc/3.0/) which permits unrestricted, non-commercial use, distribution and reproduction in any medium, provided the work is properly cited. 